\title{
CANTO AL INDIO ATACAMEÑO DE NICOLÁS FERRARO: UNA LECTURA POÉTICA DE LA CULTURA LIKANANTAI*
}

\author{
NICOLÁS FERRARO'S CANTO AL INDIO ATACAMEÑO: \\ A POETIC READING OF LIKANANTAI CULTURE
}

\author{
MAURICIO OSTRIA GONZÁLEZ ${ }^{* *}$ \\ PATRICIA HENRÍQUEZ PUENTES ${ }^{* * *}$
}

Resumen: Tal vez uno de los escritores que más hondamente ha sugerido el temple de ánimo característico del nortino es Nicolás Ferraro. En efecto, a través de sus relatos y poemas se va diseñando un conjunto de rasgos que permiten vislumbrar, sin grandes estridencias, pero con verdad estética y antropológica, una visión convincente, persuasiva y conmovedora del habitante del norte, especialmente, de la pampa y de la puna. Desde la naturalidad de los gestos cotidianos hasta la evocación mítica y legendaria del indio atacameño, la escritura de Ferraro se construye como un continuo gesto de adhesión en medio de un hábitat desolado y triste pero cargado de querencias. Este artículo se propone, precisamente, examinar su Canto al indio atacameño, en tanto lectura poética de la cultura likanantai.

Palabras Clave: Poesía chilena, literatura nortina, Nicolás Ferraro, atacameños.

AвstRaCt: Nicolás Ferraro is perhaps one of the writers who has most profoundly captured the spirit of northern Chile. Through his poetry and narrative, Ferraro has developed a collection of features that provide a convincing and moving portrayal of the region's inhabitants, particularly those of the pampa and puna, achieving aesthetic and anthropological truth while avoiding strident depictions. From the naturalness of daily gestures to the mythic and legendary evocation of the Atacama's indigenous culture, Ferraro's writing is faithful in its representation of a desolate and mournful environment that is nonetheless charged with affect and a sense of belonging. In this

\footnotetext{
* Este artículo forma parte del proyecto de investigación FONDECYT 1170385, "Los espacios heterogéneos del Norte Grande en las literaturas y prácticas escénicas", del que los autores son investigador principal y coinvestigadora, respectivamente.

** Profesor Emérito Universidad de Concepción, Concepción, Chile. Correo electrónico: mostria@ udec.cl.

*** Doctora en Literatura Latinoamericana, Universidad de Concepción, Concepción, Chile. Correo electrónico: pathenriquez@udec.cl.
} 
vein, I examine Ferraro's Canto al indio atacameño as an original reading of the Likanantai culture.

KEYwORDs: Chilean poetry, Northern literature, Nicolás Ferraro, Atacameños.

Recibido: 20.06.18. Aceptado: 21.03.19

1 . En el Chile moderno (siglo XIX y comienzos del XX) la forma más amplia de racismo y discriminación respecto de los indígenas ha sido el ignorarlos, el ningunearlos. En Chile todos somos chilenos, iguales ante la ley, se dice con orgullo fácil. "Las sociedades latinoamericanas (también la chilena), sus Estados nacionales, se levantaron sobre la negación de 'lo indígena'. El no reconocimiento condujo a la discriminación, y ésta a la marginalidad y a la pobreza" (Bengoa, 1996, p. 113). En este marco, se suele ver, todavía hoy, a los movimientos indígenas como instrumentos de ideologías extremistas. Durante los primeros enfrentamientos de la Conquista, el reconocimiento de los indígenas era obvio, se basaba en la noción de resistencia: héroe, enemigo, aliado, etc. En la Colonia, el indio se convirtió en un estrato social inferior. Después de la Independencia, el criollo entra en competencia con el indio por la posesión de la tierra. La igualdad formal establecida por los idearios republicanos implicó la desaparición de los 'pueblos de indios', la incorporación de muchos de estos al peonaje criollo, mientras otros resistían, se marginaban o refugiaban en lugares más o menos inaccesibles. En consecuencia, la sociedad chilena tendió a pensar al indio como etnia en extinción y a desconocerlo como grupo, comunidad o nación culturalmente diferente de los chilenos ${ }^{1}$.

Concordante con esta postura, durante la vigencia del naturalismo literario, influido por el positivismo, la mayoría de los escritores que en Chile y en América Latina se ocuparon del llamado problema del indio, o han incorporado al indio como tema, motivo o personaje de sus trabajos literarios $^{2}$, lo han hecho con una visión paternalista, de conmiseración por su situación social y, a menudo, mostrándose partidarios de cambios que permitan la integración del indígena a la sociedad chilena y latinoameri-

\footnotetext{
${ }^{1}$ Los indígenas en Chile no fueron reconocidos como tales hasta 1993. Actualmente, son nueve los pueblos originarios reconocidos por el Estado, entre ellos, los atacameños o likanantai y más del 10\% de la población chilena se declara perteneciente a algún pueblo originario.

${ }^{2}$ Cf. Entre otros, Raviola, 1965 y 1969; Yankas, 1970; Epple 1994; Antillanca y Loncon, 1997; Carrasco, 2000.
} 
cana, omitiendo, sin embargo, la salvaguarda de su cultura. En el fondo, se procura que los indios dejen de serlo ${ }^{3}$.

En general, la literatura chilena hasta mediados del siglo XX exhibe la profunda escisión que caracterizó a nuestra cultura desde un comienzo: la antítesis entre la visión heroica del araucano, heredada de Ercilla, a quien Neruda llamó el 'inventor de Chile', y la bárbara y decadente del indígena, degradado por la usurpación y el vasallaje. Así, se va construyendo una cultura esquizofrénica que, por un lado, admira y reverencia al araucano mítico (del que nos sentimos herederos de sus hazañas y proezas) y, por otro, desprecia y rechaza al indio, campesino pobre o sirviente en el último peldaño de la escala social urbana. "A nuestros fantásticos héroes -escribe Neruda- les fuimos robando la mitológica vestidura hasta dejarles un poncho indiano raído, zurcido, salpicado por el barro de los malos caminos, empapado por el antártico aguacero" (1990, p. 290).

2. Al menos el mapuche, mitificado en araucano, desfigurado y todo, fue integrado al imaginario nacional. Al contrario, el indígena del Norte Grande (aimara, quechua, atacameño) ha sido durante mucho tiempo borrado sistemáticamente de cualquier consideración de la cultura chilena ${ }^{4}$ : en particular los atacameños fueron absolutamente invisibilizados. Esto porque en el imaginario nacional, el Norte ha sido desde el principio la otredad que hay que explorar, explotar y conquistar y, si acaso, integrar. Es más, el Norte se identificó prontamente con el desierto y sus habitantes fueron vistos casi siempre como una emanación de ese universo: una rareza en un despoblado. Desde los cronistas de la Conquista y la Colonia, el desierto fue considerado un espacio inhabitado, hostil a toda forma de vida, cuya fuerza telúrica se ejerce trágicamente hacia quienes se atreven a adentrarse en él. Naturalmente, en esa visión quedaba excluida toda manifestación cultural.

Dentro de esa lógica -norte igual desierto; desierto igual sequedad inhabitada- el ser humano y su cultura no existen. Aun para arqueólogos,

\footnotetext{
${ }^{3}$ Es el caso, por ejemplo, de escritores como el boliviano A. Arguedas, el ecuatoriano J. Icaza, el peruano C. Alegría o el chileno L. Yankas. Es verdad que, con el neoindigenismo, a partir de los años '40 del siglo XX, en América Latina surgen voces mucho más comprensivas de la condición del indígena y de su contexto cultural. Al respecto, junto a la figura señera de José María Arguedas hay que nombrar al menos, en el mundo andino, a Manuel Scorza y Gamaliel Churata. En Chile surgirán, recién en los sesenta, autores como Luis Vulliamy, Patricio Manns, Eduardo Labarca o Sonia Montecino.

4 “Tal vez el Chile Republicano Temprano, se imaginó a sí mismo como un territorio, 'mi Patria', con un 'Centro', al cual había que anexar una Araucanía que estaba geopolíticamente pendiente por el Sur, y no calculó la futura anexión de los territorios peruanos y bolivianos al norte de Copiapó, al norte del Descampado de Atacama, que descontrapesó su imaginario topológico” (Mege, 2009, p. 181).
} 
etnólogos, historiadores las culturas del Norte son, casi siempre ${ }^{5}$, formas de un pasado reducido a objetos (monumentos, artesanías, cementerios). La materialidad se expande profusamente por los objetos deshumanizados: líticos, cerámicas, metales, maderas y textiles; utensilios y artilugios de todo tipo y arquitectura desolada, mostrando por la "cosa" al sujeto (Mege, 2009). El ser humano está ausente.

Aunque en el ámbito de la antropología y la arqueología las poblaciones atacameñas han sido casi siempre consideradas como objetos de estudio, como reminiscencia de un pasado que era importante conocer antes de que desapareciera (Ayala, 2007), los actuales atacameños se refieren a los sitios arqueológicos como lugares y obras de los "abuelos", de los "gentiles", espacios y cosas que hay que respetar y temer (Ayala, 2007). En verdad, las disputas entre investigadores y pobladores no hacen sino evidenciar la sobrevivencia de los likanantai, aunque poco quede de su cultura ancestral y su lengua -el kunza- se halle prácticamente extinguida.

La literatura, en cambio, no ha estado ajena a esa presencia continua. En uno de sus mejores cuentos - "Soledad en la puna"-, Mario Bahamonde (1978) evoca muy eficazmente la sensibilidad del habitante de la meseta andina: "Padre Apacheta ${ }^{6}$, aquí te traigo estas hojas de coca y estas lanas teñidas porque con ellas se alivia y se abriga la vida que tú nos das en estas alturas. Ayúdame también en mis andanzas" (p. 242). Y el narrador caracteriza así al protagonista:

A Condorumi todo lo identificaba con la cordillera... Para él esas montañas, esos cañadones metidos entre las cumbres, esos desfiladeros que se despeñaban de cabeza hacia el abismo, las nevazones despiadadas que solían congelar la existencia y el aire puro y ralo, todo eso junto era el amasijo donde se fundía el hombre con la piedra, la existencia con la naturaleza... en la cordillera las cosas suceden lentamente... sentía la cordillera en su destino... (pp. 243-244)

En este entorno, "la etnia atacameña es una identidad que mira hacia el pasado, un pasado glorioso de resistencia cultural cuyos vestigios materia-

\footnotetext{
${ }^{5}$ No se puede desconocer, no obstante, el legado fundamental de investigadores como Gustavo Le Paige, Lautaro Núñez, Mario Orellana y otros.

${ }^{6} \mathrm{La}$ 'apacheta' es un montículo de piedras, especie de altar sagrado para los atacameños, en tanto encarna espíritus del camino, dioses menores en la cosmovisión likanantai; por eso se les rinde tributo como se refiere en el cuento de Bahamonde-, ofreciéndoles convidosotinkas (hojas de coca, tejidos). "Se cree que tanto la piedra como la semilla, tanto el camino y la apacheta como la siembra, el ganado y el tejido de telar poseen espíritu, vida propia y poder. Por esta razón, se da una relación íntima, profunda y respetuosa entre el caminante, su camino y la apacheta" (cf. Grebe e Hidalgo 1988, p. 89).
} 
les aportan en la construcción de una imagen e historia de sí mismos”, mas, al mismo tiempo, vive su presente y se proyecta como "una identidad articulada y resultante de los procesos de modernización vivenciados a nivel regional y nacional" (Ayala, 2007, p. 144).

3. Sin duda, es Nicolás Ferraro ${ }^{7}$, uno de los escritores que con mayor certeza expresiva ha intuido el temple de ánimo ${ }^{8}$ característico del habitante del Norte (Cf. Moretic, 1962, pp. 31-35; Bahamonde, 1969, pp. 92-93). En toda su obra -narrativa y lírica- se configura, sin estridencias, pero con verdad estética y antropológica, una visión convincente y conmovedora de la pampa y la puna nortinas, y de sus gentes. Desde la naturalidad de los gestos cotidianos hasta la evocación mítica y legendaria del indio atacameño, la escritura de Ferraro se construye como un sentido gesto de adhesión a los ancestros. A partir de las ruinas de su pueblo, al que vuelve una y otra vez, Ferraro construye imágenes alucinadas, que revelan su alma empampada definitivamente en medio de la desolación:

cerrando los ojos para evitar la resolana uno puede percibir... algunos muros derruidos donde el viejo viento se estrelló llorando. El aire caliente da un aspecto terrible a lo que ya es terrible y solo. Deforma las perspectivas. Brilla todo con furia. Hay espejismos; lagos de agua pura y helada, castillos, embarcaciones y muchachas, ciudades. Enloquecemos bajo el sol amarillo e implacable. (1959, p. 12)

Y a la manera de Jorge Manrique, el poeta se pregunta nostalgioso:

¿Qué fue de aquel, mi pueblo, donde el viento en la tarde bailaba algún minueto por las duras aceras, (...) ¿Qué se hicieron los cielos, los caballos, las nubes los muertos, los retenes, los pozos y las rejas? (...) qué del salitre, el vino, los perros, las imprentas? (...) sonará algún fantasma detrás del cementerio su flauta entre las dunas y alguna tumba abierta. (...)

\footnotetext{
${ }^{7}$ Nació en Pampa Unión en 1921; falleció en Santiago, en 2012. Entre sus obras se cuentan, además del Canto al indio atacameño, la novela Terral (1959); los poemarios Sed por dentro (1959) y Tierramor (1983); las colecciones de cuentos, Inmóvil océano (1965), De regreso (1973), Hacia el mar (1973), El hombre que no quería comer (1973) y Tomás Godoy, el empapado y otras historias del Salar Grande (1979).

${ }^{8}$ Aunque el concepto de 'temple de 'animo' es desarrollado en el ámbito filosófico (v. gr. Husserl, Heidegger, Jaspers), aquí restringimos su uso exclusivamente al terreno de la literatura y, sobre todo, de la poesía. Véase Pfeiffer (1966, pp. 42-52).
} 
¿Quién derribó los muros, los hoteles, el cine;

quién aventó las hojas del pimiento y las hiedras? (...)

¿Quién robó mi pasado, mi infancia, mis vecinos? (...)

¿Quién se robó el hogar, el pecho, las campanas

los guijarros del llanto, del tiempo y de las penas! (Ferraro, 1983, pp. 5-6)

Aquí y en todos los poemas de Tierramor, sus versos resuman un temple de adhesión raigal e incondicional por su lar pampino, que posee la magia paradojal de revivirlo, no obstante su sequedad mortal:

Tierra mía de espanto, triste, inerme;

océano de fuego, mar de arena;

he de volver hasta tu seca vena

para reverdecerme. (Ferraro, 1983, p. 21)

4. Aunque de acuerdo a los estudios arqueológicos, etnológicos e históricos lo que hoy se denomina "atacameño" resulta ser el producto de múltiples y diversas poblaciones ${ }^{9}$ sin conciencia identitaria unitaria y sin configurar un grupo necesariamente ubicable espacial y culturalmente en lo que hoy es aproximadamente la región del Loa y San Pedro de Atacama, lo cierto es que, por diversas razones, el vocablo ha terminado por imponerse e, incluso, sus propios habitantes han aceptado esa denominación (Uribe y Alfaro, 2003; Ayala, 2007). Por otra parte, si bien es cierto, los atacameños o likanantai ("habitantes del territorio") se relacionaron y expandieron su cultura también por el norte argentino y sur de Bolivia, aquí -siguiendo el imaginario poético de Ferraro- aludimos solo al habitante de los oasis precordilleranos de la provincia del Loa ${ }^{10}$.

El Canto al indio atacameño de Ferraro, publicado en $1996^{11}$, a pesar de su pasatismo, supera y sutura, con las herramientas de la intuición poética, la ausencia del indígena en las visiones antropológicas, políticas y sociales

\footnotetext{
${ }^{9}$ Las comunidades atacameñas aún habitan los oasis, valles y quebradas de las cuencas del salar de Atacama y del río Loa, ubicadas en la Región de Antofagasta en Chile. Pequeñas poblaciones se encuentran también en el noroeste de Argentina, en la puna de Salta y Jujuy, y en el altiplano suroeste de Bolivia.

${ }^{10}$ Recuérdese que en poesía la verdad histórica se hace verosímil, es decir, es el producto de una intuición poética.

${ }^{11}$ La edición consta, además del poemario, de "Dedicatorias" y "Agradecimientos" (p. 2), un breve prólogo del editor, Roberto Lehenert S. (p. 3) y un "Índice" (p. 50). El libro está impreso por una sola cara.
} 
dominantes, y construye un puente que asegura la continuidad cultural del pueblo atacameño más allá de la guerra, la destrucción y la muerte. Ferraro reconstruye poéticamente un imaginario cultural y lo actualiza en la figura de un yo/nosotros hablante del poema. Ese hablante -a veces un yo, a veces un nosotros- asume el pasado en el presente textual, revive la historia de los atacameños, principalmente, desde la dominación incaica, el abandono forzado y doloroso de sus tierras y la consecuente peregrinación por el desierto y hacia la costa ${ }^{12}$.

El "Canto" está compuesto de nueve partes que, en cierta manera, constituyen el relato poético del peregrinaje de los atacameños por el desierto: 1. "La cara del tiempo", 2. "Tu huella en el tiempo", 3. "Mi padre invoca a su padre", 4. "La sed", 5. "Padre mío, hijo de la arcilla", 6. "Padre, indio, padre del mundo", 7. "Padre mío que estás en el mar", 8. "Padre mío, que estás en la piedra" y 9. "Nuestra batalla". La mayoría de ellas consta de largas tiradas de versos de arte mayor, con amplio predominio de endecasílabos (no faltan, empero, los alejandrinos, heptasílabos y otros versos cortos y largos). Entre las partes, se intercalan poemas de carácter más propiamente lírico ("Pequeño adiós", poema pórtico, en octosílabos; "Luna azul en el desierto", en tercetos endecasílabos y alejandrinos; "Caminar cansa en la niebla", en tercetos endecasílabos; "Uno cae en el sendero" (en romance); "Canción para entrar en el desierto" (tercetos irregulares con predominio de endecasílabos); "Salar" (en tercetas y cuartetas octosílabas, algunas de pie quebrado); "Instrucción y primer asentamiento" (en romance); "Nocturno, en el mar" (en verso libre rimado) y un "Soneto final".

La Introducción del Canto $^{13}$ esboza el motivo del destierro:

Es tanto lo que dejamos:

nuestros sembrados, las casas,

los huertos, el áspero ají rojizo,

el trigo ${ }^{14}$, el aire y las aguas. (p. 5)

\footnotetext{
${ }^{12}$ Según la documentación histórica de que disponemos, tal peregrinación -producto de la invasión inca- no se produjo; de modo que, en el contexto ficcional del poema, debe entenderse como el tránsito del puneño o el pampino hacia la costa en cualquier tiempo, incluido el del propio hablante lírico.

${ }^{13}$ Todas las citas corresponden a Ferraro (1996).

${ }^{14}$ Puede parecer un anacronismo el que se mencione al trigo. No lo es, si se considera la perspectiva sincrética del hablante y, en consecuencia, del poema. Así, la palabra 'trigo' ya aparece en los vocabularios del kunza que han sobrevivido. Además de trigo = Tchacko, se registran las expresiones Trigo pelado = Lockro y Trigo tostado Tchotar (Cf. Vilte y Pérez, 2004).
} 
El texto se construye sobre tres elementos: el dolor ('llanto') por la partida, la necesidad de reconstrucción ('piedra sobre piedra') y la resistencia al invasor (el inca):

-Un refugio contra el inca.

Contra el inca y sus esclavos.

Nunca más seremos chasquis.

Ni peones explotados...

-Piedra sobre piedra,

hermano.

Piedra sobre piedra. Y llanto. (pp. 36-37)

A diferencia del 'canto' nerudiano a Macchu Picchu, el texto de Ferraro no se propone "hablar por vuestra boca muerta", ni invoca a los muertos para erguirse en su vocero ("Hablad por mis palabras y mi sangre") (Neruda, 2000, pp. 140-141). Al contrario, el hablante del Canto al indio atacameño asume sobre sí la condición de indígena y, por tanto, 'vive' o 'revive' los sufrimientos de su pueblo y se identifica con él y su devenir: "Eres quien soy y soy quien eres... y el tiempo... no puede ya borrarte de mí mismo / no puede ya alejarme de tu rostro" (p. 44). A través de una mirada que es simultáneamente retrospectiva, dinámica y actual, exhibe el proceso de transculturación y mestizaje que va transformando a las gentes y a las culturas. El discurso personal -yo/nosotros- y su devenir temporo-espacial posibilita no solo la representación de los atacameños, como pueblo marginado y en constante peregrinaje, sino también proyecta una mirada cuestionadora hacia el pensamiento chileno sobre los indígenas y la cultura del Norte; el discurso sugiere asumir los imaginarios étnicos como sustento del desarrollo social y cultural chileno actual (Infante, 2013). La asunción de la perspectiva indígena implica 'revivir' el estado de ánimo, el sufrimiento de los migrantes y, por tanto, refuerza el carácter dolorido del poema: "Ay, indio de Atacama que me dueles / metido entre mis cejas y mi llanto" (p. 43).

El breve tiempo transcurrido por la expansión del incanato en la región -de aproximadamente sesenta años hasta la llegada de los españoles- no logró imponer totalmente la cultura incaica sobre la sólida identidad étnica y cultural atacameña: los likanantai mantuvieron su lengua originaria: el kunza (Bustos, 1999, p. 42), idioma que convivió con el aimara, el quechua y el español hasta las primeras décadas del siglo $\mathrm{XX}^{15}$. Hoy ya no se habla; apenas

\footnotetext{
15 "[L]a región atacameña ha sido un espacio de tránsito y de encuentro entre culturas, lo cual parece haber repercutido en un uso paralelo de cuatro lenguas. Aún hoy día, ellos afirman: 'Estamos metidos en quichua, aymara, kunza y español' (Talabre)" (Grebe e Hidalgo, 1988, p. 96).
} 
sobrevive en algunos rituales y ceremonias y en la toponimia del territorio ${ }^{16}$. Aunque el poema, obviamente está escrito en español, el autor incorpora especialmente en el léxico (toponimia, zoonimia, fitonimia, nombres de objetos y alimentos), una serie de expresiones equivalentes a las sobrevivientes kunza, tratando de evocar la forma interior del lenguaje de los atacameños:

abuelo de mis padres, de mis hijos...

Ay indio de Lasana, Chiu Chiu ${ }^{17}$, Caspana ${ }^{18}$ y Agua Amarga y Toconao ${ }^{19}$, Quillagua, Collahuasi y Cachinal, Socompa, Chullaillaco y Carmen Alto ${ }^{20}$. Ay, indio mío, padre mío, huella de tus cansados, infinitos pasos... (p. 43)

Al mismo tiempo, el verso octosílabo se organiza, sobre todo, con frases u oraciones simples, desnudas, buscando sugerir la visión trágica, sobria, estoica del peregrinaje: el hogar que se deja; el incierto destino, el dominio del desierto ("piedra sobre piedra") y el ensueño del rencuentro:

La tropa se pone en marcha.

-¿Qué encontraremos allá?

Cerramos los ojos. -Nada.

Ni graneros ni picachos.

Sólo piedras. Secas. Blancas.

-¿Qué encontraremos allá?

La tierra nuestra y preñada. (p. 5)

Piedra sobre piedra, hermano.

-Las pircas contra los zorros

Corral para los huanacos.

Depósito para el trigo, para el maíz y el salvado.

Piedra sobre piedra, hermano... (p. 36) ${ }^{21}$

\footnotetext{
16 "Los últimos hablantes parecen haber vivido (o por lo menos personas que recordaban algo de la lengua) en los años 50. El idioma se mantiene en parte en oraciones e invocaciones cantadas en los ritos de limpia de los canales, pero su significado queda en gran parte oscuro, incluso para los propios participantes" (Fabre, 2005, p. 1).

${ }^{17}$ Gorrión.

${ }^{18}$ Posiblemente, 'hijo de la hondonada'.

${ }^{19}$ Toconao, que en lengua kunza significa rincón perdido... es una de las tres ciudades legendarias de la cultura atacameña (Cf. Vilte y Pérez, 2004).

${ }^{20}$ Nótese que el texto incluye vocablos de origen kunza junto a otros quechuas, aymaras y castellanos.

${ }^{21}$ No falta la alusión a las formas de sepultación andina: "En el peregrinar alguien muere: / Tuvimos que hacer con él / un paquete a toda prisa. / Y lo enterramos volando. / Lo dejamos en cuclillas" (pp. 20-21).
} 
Igualmente, la presencia de sintagmas no progresivos (reiteraciones, enumeraciones, paralelismos y disfrasismos, al modo de los textos prehispánicos aztecas, mayas o quechuas o de los medievales españoles ${ }^{22}$ ) busca evocar el discurso antiguo y modelar una imagen del tiempo, que es también tiempo interior ("Y uno transcurre, pasa, crece, pasa"):

Agua del tiempo, polvo del tiempo, rostro del tiempo oscuro, aparte, ensimismado. El tiempo que está siempre afilando sus cuchillos. El tiempo que nos crece, nos está matando. El tiempo como un frío animal en las penumbras. oscuro, falso, torvo, agazapado. Y uno transcurre, pasa, crece, pasa. (...) movido por las perras, el espanto, el anhelo, movido por el viento y su ocarina, llovido por el cierzo, el negro duelo. (pp. 8-9)

El tiempo aciago del destierro parece moverse en dirección contraria a la concepción positiva de los atacameños (en contra de las manecillas del reloj $^{23}$ ): "La división del tiempo circular en dos mitades, que representan, respectivamente, al día y la noche, se asocia a dos ámbitos semánticos opuestos: mientras el día y la luz solar se vinculan a 'las buenas horas', la noche y su oscuridad (oscurana) se asocian a 'las malas horas"' (Grebe e Hidalgo, p. 78). Correlativamente, mientras el oriente o naciente se vincula a la vida y al movimiento vertical (las montañas, el agua, los dioses), el poniente posee una carga negativa (la noche, la oscuridad, la muerte, el movimiento horizontal). En consecuencia, el peregrinar por el desierto, desde las montañas hacia el mar (también el descenso es negativo), resulta una marcha marcada no solo por el alejamiento del hogar y de los dioses, sino por la presencia ominosa de la destrucción, la orfandad y la muerte. Por eso la memoria del padre (los abuelos, los dioses) es una memoria de 'ceniza y camelia', de 'furias y de hierros', que 'baja y llora por el desierto':

Tu memoria, mi padre, de ceniza y camelia.

Tu memoria, mi padre, de furias y de hierros.

Tu memoria que clausura las viejas ventanucas, las puertas.

Y el canal que no trae más agua para el riego.

Pero que baja aún por el desierto llora. (pp. 11-12)

\footnotetext{
${ }^{22}$ Cf. Garibay, 1968; y Alonso y Bousoño, 1953.

${ }^{23}$ Cf. Grebe e Hidalgo, 1988, p. 78.
} 
La síntesis de lo dicho aparece expresada en el verso: "Todo aquello que fue, que nos pasó y hoy está muerto y llora" (p. 12).

La presencia del antepasado -representado en una figura paterna- permea la totalidad de la existencia del yo (indio) y define su nostalgia: "En todas partes, padre, hay huellas de tu paso" (p. 29):

A veces caminamos. Como yendo a Taltal y encontramos en medio de unos huesos una gota vetusta de tu arte ${ }^{24}$, y la evidencia de un trabajo eterno: la forma que es punta de una flecha carcomida y la materia: el llano, gris desierto. (p. 15)

Se evidencia así lo señalado por Grebe e Hidalgo (1988): "Por ser espíritus de los antepasados, a los tata-abuelos se les teme por su gran poder y se les respeta por los restos visibles de su obra cultural representada por los canales de riego, las pircas de las eras y las casas de piedra" (p. 89).

Por otra parte, la influencia incaica, breve pero determinante, provoca el sincretismo de los dioses; el atacameño hace suya la voz del antepasado y se apropia de la invocación al dios incaico todopoderoso, en oración que emplea el mismo disfrasismo arcaizante ya detectado en otros segmentos del texto:

Viracocha, Señor, oh, Viracocha, me inclino ante tu rostro soberano.

Me postro ante tu incendio interminable.

Me arrastro ante tu furia y tus zarpazos.

Me humillo a tu calor que desespera Me abate tu poder horrendo y basto... Tú creces en la hierba de los campos Tú das vida, Señor. Tú das la muerte cuando uno suda al irse caminando por el desierto gris. Como ceniza... (p. 17)

A ese padre sincrético, señor de la vida y la muerte, dios castigador e implacable, se implora, mientras, camino del destierro, se avanza penosamente por el desierto, 'la tierra sin pueblos':

${ }^{24}$ Probable alusión a los petroglifos ubicados en el Médano de Taltal. 
Y que mientras viajamos por la tierra sin pueblos, no nos hieran las hojas de los cardos, sus espinas agudas, sus espadas siniestras y que tu luz benéfica continúe alumbrándonos... Oh, Señor que protege a mis hermanos, a mis padres, mis mujeres, mis hijos y los míos y cuidas de ellos mientras vamos andando. (p. 19)

En el Canto al indio atacameño el desierto constituye, sin duda, una imagen de alteridad respecto de la montaña y el hogar del atacameño prehispánico. En tal sentido, el desierto es pintado con colores oscuros, grises y negros, vinculados en la simbología atacameña a los aspectos negativos de la vida y la muerte ${ }^{25}$ : "Y dejamos atrás a las montañas. / Aquí comienza el arenal sin vida. / El triste despoblado. Los fantasmas” (p. 27). Allí la sed es el antagonista dominante: "Todo era sal y sed y muerte y desamparo/en ese horrible, pavoroso yermo" (p. 26).

La sed nos fue vistiendo

Con una saya blanca, seca, funeral por dentro.

Saliva espesa, esputo escaso, denso...

La arena que cubría tus encías se fue descascarando. Pero permanecía en ellas.

Cayendo.

La sequedad nos fue cegando. El turbio llanto era un horrible y denso filamento.

Las manos se llagaban. Los labios se rompían en pedazos... La lengua era de trapo. Un trapo inmenso.

Íbamos casi muertos.

No teníamos lágrimas. Del ojo iban saliendo perlas saladas, piedras saladas, Sólo tierra impalpable... (pp. 22-23)

Mas también el viento fustiga "con su furia primitiva, iracunda" (p. 17), a los dolientes peregrinos que recorren "la meseta larga, sin vida"; mientras "el cansancio / amarra nudos en las piernas duras / y lianas y ataduras por

\footnotetext{
25 "El primer grupo está integrado por el blanco y los matices de la gama del rojo (rosado, rosaseco, rojo, solferino, granate), a los cuales se asigna connotaciones positivas, asociándoseles al contexto ritual. El segundo grupo está representado por los colores negro y blanco combinados, que representan a los difuntos y a la muerte" (Grebe e Hidalgo, 1988, p. 85).
} 
los brazos" (p. 17). Así, en el peregrinar por esa tierra hosca y desconocida, la naturaleza -brazo del dios terrible- ejerce su poder implacable, sembrando el tránsito de peligros y acechanzas. Tanto que, incluso, la neblina (la camanchaca) que podría salvar a los peregrinos de la agonía de la sed, se torna en motivo de extravío:

Y en mitad de esta tela ensangrentada, uno marcha. Más corre que camina, y deja atrás la noche ensimismada. (...)

Entramos en la lluvia desatada.

Perdemos el camino. Niebla fina

que opaca luces, senderos y cansada

ensaya rumbos por la altura andina. (p. 16)

Por este camino, el Canto se torna elegía, poema nostalgioso, mentador de agonías y de pérdidas definitivas:

Y ya no volverás a tus rincones.

A tu huerta, a tu casa, a los huanacos ${ }^{26}$.

A una tierra que no te pertenece. (...)

El mar te blanqueará la piel oscura. (p. 40)

No obstante, revirtiendo el simbolismo tradicional atacameño (la negatividad del descenso hacia el poniente, hacia lo horizontal), el Canto concluye con un temple optimista, con una invitación a levantarse, a 'dar la batalla'. Por fin, juntos definitivamente en el espacio utópico, no habrá quién pueda vencer a los likanantai. Y vendrá el enemigo, el de antes y el de ahora:

\footnotetext{
Y soplará su cuerno

y lanzará sus rayos

y soltará a la muerte, nos traerá a sus pájaros.

Pero estaremos juntos.

Nos venderemos caros.

Le arrojaremos piedras

lo dejaremos harto, uno con otro, padre;

padre, brazo con brazo.
}

${ }^{26}$ Nítido homenaje al poeta español Miguel Hernández y a su "Elegía” a Ramón Sijé. 
Y seguiremos juntos por el mundo

hasta el fin de las eras,

hasta el nuevo milagro

otra vez dueños, otra vez solos,

movidos por el aire americano,

¡nuestro, sólo nuestro, entero nuestro,

libres como una estrella en el espacio! (pp. 47-48)

Como se aprecia, ampliadas las fronteras del mundo atacameño y andino, el canto deviene elegía y la elegía, utopía y grito de liberación.

Es más, en el soneto final se imagina la reunión definitiva con el padre (los abuelos, los ancestros) en un abrazo definitivo en que los atacameños y sus descendientes parecen encontrarse en el océano, más allá de la muerte:

Desde uno y otro lado de la muerte

-rodeados, tú de tierra y yo de cielo, (...)

un día que vendrá, que ya lo espero,

hechas polvo y vilanos las cernadas

de mis huesos caerán a tu huesera. (p. 49)

En síntesis, por la senda de la reconstrucción imaginaria, hondamente emotiva, el Canto al indio atacameño deviene la expresión lírica (elegíaca e hímnica) del amor entrañable -más allá del tiempo- al desierto y a sus antiguos pueblos, en tanto lugar de origen del hablante, identificado absolutamente con sus ancestros y su cultura, aunque, recordando al poeta clásico, "Solo quedan memorias funerales, / (...) de todo apenas quedan las señales. / (...) leves vuelan cenizas desdichadas" (Rodrigo Caro, "Canción a las ruinas de Itálica”, cit. por Del Campo, 1957, pp. 59-60).

\section{REFERENCIAS}

Alonso, D. y Bousoño, C. (1953). Seis calas en la expresión literaria española. Prosa, poesía, teatro, Madrid: Gredos.

Antillanca, A. y Loncon, C. (1997). Entre el mito y la realidad. El pueblo mapuche en la literatura chilena. Santiago: Lom.

Ayala R., P. (2007). Relaciones entre atacameños, arqueólogos y Estado en Atacama (norte de Chile). Estudios Atacameños, 33, 133-157.

Bahamonde, M. (1969). El relato literario en el Norte de Chile, en Ostria, M. (ed.). La naturaleza y el hombre en la novela hispanoamericana, Primer Seminario Internacional de Literatura hispanoamericana (pp. 79-98). Antofagasta, Universidad del Norte. 
Bahamonde, M. (1978). Derroteros y Cangalla. Santiago: Nascimento.

Bengoa, J. (1996). La comunidad perdida. Ensayos sobre identidad y cultura: los desafíos de la modernización en Chile. Santiago: Ediciones Sur.

Bustos, A. (1999). Etnografía atacameña. Antofagasta: Editorial Universidad de Antofagasta.

Carrasco, I. (2000). Poesía mapuche en la literatura chilena, Estudios Filológi$\cos , 35,139-149$.

Del Campo, A. (1957). Problemas de "La canción a Itálica", Revista de filología española, 1/4(XLI), 47-139.

Epple, J. A. (1994). Actas del BíoBío y el canon indigenista de Chile. El arte de recordar. Santiago: Mosquito Editores.

Fabre, A. (2005). Diccionario etnolingüístico y guía bibliográfica de los pueblos indígenas sudamericanos, http//www.academia.edu/.../Atacameño_ Kunza_Likan_antai_AUTODENOMI

Ferraro, N. (1959). Terral, Santiago: Alerce.

Ferraro, N. (1983). Tierramor. Antofagasta: I. de Investigaciones Antropológicas, Facultad de Educación y Ciencias Humanas, U. de Antofagasta.

Ferraro, N. (1996). Canto al indio atacameño. Antofagasta: I. de Investigaciones Antropológicas, Facultad de Educación y Ciencias Humanas, U. de Antofagasta.

Garibay, Á. M. (1968). Poesía náhuatl, México, D.F.: UNAM.

Grebe, M. E. e Hidalgo, B. (1988). Simbolismo atacameño: un aporte etnológico a la comprensión de significados culturales, Revista de Antropología, 7, 75-97.

Infante, C. (2013). “Todo aquello que fue, que nos pasó y hoy está muerto y llora": alabanza, resistencia, rescate. Una aproximación a Canto al indio atacameño de Nicolás Ferraro, Concepción, U. de Concepción (inédito).

Mege, P. (2009). Viviendo en el mundo material. Fotografías de indígenas del Desierto de Chile, Aisthesis, 46, 178-200.

Moretic, Y. (1962). El relato de la pampa salitrera. Buenos Aires: Ediciones del Litoral.

Neruda, P. (1990). Para nacer he nacido. Barcelona: Bruguera.

Neruda, P. (2000). Canto general. Madrid: Cátedra, 6a ed.

Pfeiffer, J. (1966). La poesía. Hacia la comprensión de lo poético. México: F.C.E., $4^{\mathrm{a}}$ ed.

Raviola, V. (1965). Lo araucano en la literatura chilena, Revista Stylo, 1, 55-73.

Raviola, V. (1969). El tema mapuche en algunas obras literarias chilenas. Siglo XX. Revista Stylo, 9, 95-132.

Uribe Rodríguez, M. y Adán Alfaro, L. (2003). Arqueología, patrimonio cultural y poblaciones originarias: reflexiones desde el desierto de Atacama, Chungara, Revista de Antropología Chilena, 35, 2, 295-304.

Vilte Vilte, J. y Pérez, C. (2004). Diccionario: Kunza-Español / Español-Kunza (Lengua del pueblo Lickan Antai o Atacameño), s/l, Codelco Chile. Disponible en: http://www.memoriachilena.cl/archivos2/pdfs/MC0038216.pdf 
Yankas, L. (1970). El pueblo araucano y otros aborígenes en la literatura chilena, Cuadernos Hispanoamericanos, 247, 113-137. 